\title{
A ULTRA-SONOGRAFIA COMO MÉTODO DE RASTREAMENTO POPULACIONAL DE TUMOR RENAL
}

\author{
THE ULTRASSONOGRAPHY AS POPULATION METHOD OF RENAL TUMOR \\ SCREENING
}

\author{
Luiz Carlos Maciel ${ }^{1}$; Luiz Fernando Nascimento²; Chelna Paolichi Ferro Elias ${ }^{3}$; \\ Bruno Simão Rodrigues ${ }^{4}$; Flávio Luís Gurgel de Oliveira ${ }^{3}$; Rodolfo Otávio Tomaz Bertti, AsCBC-SP
}

\begin{abstract}
RESUMO: Objetivo: Estimar a prevalência dos incidentalomas renais malígnos no Hospital Universitário de Taubaté (HUT), evidenciados pelo ultra-som. Método: Estudo transversal e retrospectivo de 1559 prontuários de pacientes submetidos a US abdominais, por indicações que não envolviam sinais ou sintomas relacionados ao tumor renal, no período de maio de 1999 a novembro de 2002. Avaliou-se idade, sexo, indicação do exame, característica da lesão. Resultados: Encontrou-se 102 casos de incidentalomas renais, com a prevalência $6,2 \%$ de cistos simples e $0,19 \%$ de massas malignas do total dos US realizados. Conclusão: A prevalência do incidentaloma renal maligno no Hospital Universitário foi de $0,19 \%$, sendo menor que a descrita na literatura. O uso de ultra-sonografia como método de rastreamento populacional deve ser mais bem estudado, pois necessita de elevado número de exames para diagnóstico precoce do tumor renal (Rev. Col. Bras. Cir. 2007; 34(6): 398-400).
\end{abstract}

Descritores: Incidentaloma renal; Neoplasias renais; Ultra-sonografia.

\section{INTRODUÇÃO}

Incidentaloma renal é o achado de tumor neste órgão durante a realização de exame de imagem solicitado por outras suspeitas nosológicas, tais como hepatopatias, colecistopatias entre outras ${ }^{1}$.

O avanço tecnológico facilitou o acesso aos exames de imagem como a tomografia computadorizada (TC) e a ultrasonografia (US) e, consequentemente, verificou-se aumento no número de incidentalomas renais diagnosticados. O incidentaloma é responsável por até $50 \%$ das massas renais diagnosticadas atualmente. A ressonância magnética e a angiografia também são capazes de evidenciar este tipo de tumoração, porém o acesso a estes exames é restrito pelo seu custo e complexidade ${ }^{2,3}$. Desta forma, com a popularização destes métodos diagnósticos, a detecção e o tratamento precoces dos tumores renais melhoraram o prognóstico para estes pacientes ${ }^{2}$.

A ultra-sonografia abdominal é, indubitavelmente, uma valiosa ferramenta para o rastreamento e detecção de tumores renais, tanto benignos quanto malignos, pela sua fácil acessibilidade, seu baixo custo e ausência de complicações ${ }^{4,5}$. Diferentes tipos de tumores podem ser observados ou suspeitados por este método. Dentre os tumores malignos, os mais comuns são: o carcinoma renal (CR), o de Wilms e os tumores uroteliais de vias excretoras. Em relação aos tumores benignos os mais freqüentes são: os cistos sim- ples, o adenoma papilar renal, o angiomiolipoma e o oncocitoma $^{5}$.

O objetivo deste estudo consiste em estimar a prevalência dos incidentalomas malignos renal no (HUT), diagnosticado através da ultra-sonografia, e avaliar se este é um método financeiramente viável.

\section{MÉTODOS}

Trata-se de um estudo transversal, quantitativo e retrospectivo de 1559 pacientes submetidos à ultra-sonografia de abdome, por indicações diversas, no período de maio de 1999 a novembro de 2002, no (HUT).

Os exames foram realizados por dois médicos radiologistas, os quais se utilizaram do aparelho de ultra-sonografia marca DIASONICS 2D GATEWAY FX.

Os critérios para inclusão no presente estudo foram estabelecidos, previamente, e definidos como: exame de imagem solicitado no próprio hospital e que não tivesse relação com sintomas de tumores do trato urinário. Exclusão: exame que não pesquisou os rins e pacientes cujos prontuários foram encontrados sem laudo do ultra-som.

Pesquisaram-se inicialmente 4693 prontuários de pacientes que realizaram exames de ultra-sonografia no Serviço de Radiologia do HUT. Após a aplicação dos critérios estabelecidos, entretanto, atingiu-se a amostra de 1559 pacientes com seus respectivos exames de ultra-som.

1. Professor Auxiliar Docente da Disciplina de Urologia da Universidade de Taubaté-SP.

2. Professor Assistente da Disciplina de Epidemiologia da Universidade de Taubaté-SP.

3. Acadêmica do $6^{\circ}$ ano Médico da Universidade de Taubaté-SP.

4. Residente de Urologia do Hospital Universitário de Taubaté -SP.

Recebido em 06/03/2007

Aceito para publicação em 09/05/2007

Conflito de interesses: nenhum

Fonte de financiamento: nenhuma

Trabalho realizado Disciplina de Urologia, Hospital Universitário de Taubaté, São Paulo - SP. 
Os dados foram colhidos e registrados em protocolos pré-formulados e padronizados, segundo os critérios: idade, sexo, indicação do exame, achado à ultrasonografia (tipo de lesão e localização) e histologia das massas malignas.

A amostra foi calculada considerando prevalência de $0,5 \%$ e erro de $0,36 \%$ nos 1559 prontuários analisados.

\section{RESULTADOS}

Quanto ao sexo a amostra constituiu-se de 667 homens $(42,3 \%)$ e 892 mulheres $(57,2 \%)$, sendo a média de idade de 45 anos (05 dias a 90 anos) e a mediana de 48 anos.

As indicações para a realização de ultra-sonografia abdominal estão descritas na tabela 1. Dor abdominal inespecífica foi a indicação da ultra-sonografia em 522 casos $(33,4 \%)$, colecistopatia em 168 casos $(10,7 \%)$, estadiamento de tumores não urológicos em 130 casos $(8,3 \%)$, estudo da morfologia renal em nefropatas em 61 casos $(3,9 \%)$ e outros, que correspondiam ao seguimento dos tumores não urológicos e ao estudo das doenças da parede abdominal.

$\mathrm{O}$ achado de rim único ocorreu em vinte e seis pacientes, dos quais: três por agenesia, 14 por nefrectomias prévias e nove não especificados. Portanto considerando as unidades renais estudadas, analisaram-se 3092 rins, dos quais 2719 (87.8\%) não apresentavam alterações. Nos demais, encontraram-se cálculos urinários, cistos simples, nefropatia crônica e massas renais malignas (Tabela 2).

Tabela 1 - Indicações dos exames de ultra-sonografia.

\begin{tabular}{lrr}
\hline Indicações & $\mathbf{N}^{\mathbf{0}}$ & $\mathbf{( \% )}$ \\
\hline Dor Abdominal & 522 & 33,4 \\
Colecistopatia & 168 & 10,7 \\
Tumores Não Urológicos & 130 & 8,3 \\
Nefropatia & 61 & 3,9 \\
Obstétrico & 32 & 2,1 \\
Hepatopatia & 27 & 1,8 \\
Pancreatopatia & 12 & 0,8 \\
Outros* & 607 & 38,9 \\
Total & 1.559 & 100,0 \\
\hline
\end{tabular}

* Inúmeras indicações não urológicas.

Tabela 2 - Achados de ultra-sonografia dos 3092 rins de pacientes estudados.

\begin{tabular}{lrc}
\hline Achados & $\mathbf{N}^{\mathbf{0}}$ & $\mathbf{( \% )}$ \\
\hline Normais & 2.715 & 87,8 \\
Cálculos & 227 & 7,3 \\
Cistos simples & 99 & 3,2 \\
Nefropatia crônica e outros & 48 & 1,6 \\
Massas malignas & 03 & 0,09 \\
Total & 3.092 & 100 \\
\hline
\end{tabular}

Dos 112 pacientes com massa renal incidental, 109 eram cistos simples e três massas sólidas. Os últimos foram submetidos à tomografia de abdome ou a ressonância magnética e, posteriormente, ao tratamento cirúrgico. O estudo anátomo-patológico das peças cirúrgicas revelou: um leiomiossarcoma e dois carcinomas de células claras.

Em relação à topografia dos incidentalomas encontrados, foram observados no rim direito 59 cistos simples e dois carcinomas de células claras e no rim esquerdo, 50 cistos simples e um leiomiosarcoma (Tabela 3). Dez pacientes apresentaram cistos renais simples bilaterais.

A prevalência das massas malignas renais incidentais foi de $0,19 \%$, estando dentro do intervalo de confiança proposto pelo estudo.

\section{DISCUSSÃO}

O maior acesso à tecnologia dos exames de imagem, nas últimas duas décadas, aliados à insidiosa instalação de sintomas nas massas renais, tem resultado em descobertas rotineiras de tumores precocemente, chamados de incidentalomas. A maioria dessas lesões é composta por cistos benignos simples. Os tumores sólidos renais são encontrados em $0,3 \%$ dos exames de tomografia computadorizada e ultra-sonografia ${ }^{6}$. No presente estudo observou-se uma prevalência de $0,19 \%$ de incidentalomas nos exames ultrasonográficos realizados no HUT durante o período de estudo proposto, com a utilização apenas de ultra-sonografia.

Um estudo sobre o aumento da incidência dos tumores nos Estados Unidos ${ }^{7}$ evidencia a possibilidade de outros fatores como a hipertensão arterial sistêmica e a obesidade, principalmente em negros, contribuírem para o aumento do surgimento dos cânceres de células renais. Portanto, possivelmente não somente os achados incidentais, atualmente, podem ser os responsáveis pelo aumento da prevalência das neoplasias malignas.

No nosso estudo, três pacientes tiveram o diagnóstico de massa renal sólida durante a realização de ultra-sonografia com outra finalidade que não a análise dos rins. O primeiro paciente apresentava uma dor abdominal inespecífica, o segundo paciente, uma mulher, obteve o seu diagnóstico efetuado durante uma ultra-sonografia para avaliação gestacional (na $20^{\circ}$ semana de gestação do quarto filho) e o terceiro paciente deu entrada no Hospital com quadro clínico compatível com colecistite aguda. Com exceção da mulher, que por estar

Tabela 3 - Distribuição topográfica dos achados ultrasonográficos.

\begin{tabular}{lrrrr}
\hline & \multicolumn{2}{c}{ Direito } & \multicolumn{2}{c}{ Esquerdo } \\
& \multicolumn{1}{c}{$\mathbf{N}^{\mathbf{0}}$} & $\mathbf{( \% )}$ & \multicolumn{1}{c}{$\mathbf{N}^{\mathbf{0}}$} & $\mathbf{( \% )}$ \\
\hline Normal & 1348 & 86,4 & 1367 & 88,6 \\
Cálculos & 129 & 8,2 & 98 & 6,2 \\
Cistos Simples & 59 & 3,4 & 50 & 2,8 \\
Massa renal maligna & 2 & 0,1 & 1 & 0,08 \\
Não visualizados & 8 & 0,5 & 18 & 1,1 \\
Outros & 28 & 1,6 & 20 & 1,2 \\
\hline
\end{tabular}


grávida foi submetida à ressonância magnética nuclear, os outros dois pacientes realizaram tomografia computadorizada de abdome antes do tratamento cirúrgico para melhor esclarecimento da massa renal sólida.

Há o relato de um caso raro de incidentaloma renal em grávida com oito semanas de gestação submetida a lombotomia na $13^{\mathrm{a}}$ semana de gestação ${ }^{8}$. $\mathrm{O}$ autor discute quais seriam os efeitos dos hormônios, como a progesterona, no crescimento tumoral e o tempo ideal de gestação para efetuar a cirurgia com menor risco possível de aborto ou de parto prematuro ao concepto. A nossa paciente, mediante a ciência de todos os riscos e complicações, optou pela realização da operação no período pós natal.

Há uma prevalência de massas renais diagnosticadas acidentalmente de $0,25 \%$ em exames de ultra-sonografia ${ }^{4}$.

A análise histopatológica das peças revelou: leiomiossarcoma no primeiro paciente e carcinomas alveolares de células claras nos demais. Desta forma, a prevalência das lesões malignas da amostra deste estudo foi de $0,19 \%$.

Certamente, a maior vantagem dos achados de massas incidentais se deve a possibilidade de tratamento precoce de lesões sugestivas de malignidade. $\mathrm{O}$ estadio, o grau e a sobrevida em cinco anos ( $85 \%$ versus $44 \%$ ) são mais favoráveis nos portadores de incidentalomas do que nos portadores de tumores sintomáticos ${ }^{2}$. Paradoxalmente, neste estudo to- dos os pacientes apresentavam tumores acima de T2 e comprometimento linfonodal (estádio cirúrgico), mas nenhuma metástase à distância.

As características inerentes a bom método de rastreamento são a simplicidade e a rapidez de realização, o fácil aprendizado, alta sensibilidade, custo e permissão da leitura imediata dos resultados, possibilitando a tomada de decisões terapêuticas na mesma visita, o que diminui as perdas de seguimento e abandono de tratamento, problemas muito comuns em locais de poucos recursos ${ }^{9}$.

O custo operacional levantado para a realização da ultrasonografia abdominal no HUT girou em torno de R $\$ 30,00$ por exame. Apesar de um custo baixo, a sua utilização como método para rastreamento populacional de tumor renal necessita da realização de elevado número de exames, pois a prevalência das lesões malignas é baixa, prejudicando assim a sensibilidade do exame. No sistema público de saúde, que trabalha com verbas excessivamente reduzidas, o fator custo é um ponto importante a ser discutido.

Embora a ultra-sonografia seja um método de diagnóstico por imagem, cujo custo é aceitável, o seu uso para rastreamento populacional no diagnóstico precoce de tumor renal apresenta a necessidade de um elevado número de exames a serem realizados para diagnóstico de poucos casos. Há, portanto a necessidade de mais estudos no intuito de definir um método de rastreamento populacional do tumor renal com maior eficiência.

\begin{abstract}
Background: To estimate the prevalence of kidney incidentalomas detected by ultrasound (US) at the University Hospital of Taubaté. Methods: Transversal and retrospective study of 1559 patients with abdominal US, with indications that did not lead to signals or symptoms related to renal tumors. This study was done during May of 1999 through November of 2002. We evaluated age, sex, indication of the examination, and characteristic of the injury. Results: One hundred and two cases of kidney incidentalomas were found, with $6.20 \%$ of kidney cysts and $0.19 \%$ of malignant kidney tumors. Conclusion: The prevalence of incidentaloma with kidney malignancy at the University Hospital was of $0.19 \%$. These results are lesser than that have been described in the literature. The use of US as a screening population method has to be better studied, because it is necessary too many examinations to achieve very low positive diagnosis for kidney cancers.
\end{abstract}

Key words: Kidney incidentaloma; Kidney neoplasms; Ultrasonography.

\section{REFERÊNCIAS}

1. Klievit J, Haak HR. Diagnoses and treatment of adrenal incidentaloma. Int Endocrinol Metab Clin North Am. 2000;29(1):69-90.

2. Bretheau D, Lechevallier E, Eghazarian C, Grisoni V, Coulange C. Prognostic significance of incidental renal cell carcinoma. Eur Urol. 1995;27(4):319-23.

3. Landis SH, Murray T, Bolden S, Wingo PA. Cancer statistics. CA Cancer J Clin. 1999;49(1):8-31.

4. Fujii Y, Ajima JI, Oka K, Tosaka A, Takehara Y. Benign renal tumors detected among healthy adults by abdominal ultrasonography. Eur Urol. 1995;27(2):124-7.

5. Robbins SL. Patologia renal estrutural e funcional. In: Robbins SL, editor. $5^{\mathrm{a}}$ ed. Rio de Janeiro: Guanabara Koogan. 1996. p. 888-90.

6. Prado A. Radiologia urológica. In: Netto Junior NR, editor. Urologia prática. $4^{a}$ ed. São Paulo: Atheneu. 1999. p. 329-36.

7. Chow WH, Devesa SS, Warren JL, Fraumeni JF. Rising incidence of renal cell cancer in the United States. JAMA. 1999;281(5):1628-31.
8. Pobil Moreno JL, Martinez Rodríguez J, Maestro Duram JL, Morales Lopez A. Incidentaloma renal y embarazo. Arch Esp Urol. 1996;49 (7):755-7.

9. Cordeiro MRA, Costa HLFF, Andrade RP, Brandão VRA, Santana $R$. Inspeção visual do colo uterino após aplicação de ácido acético no rastreamento das neoplasias intra-epiteliais e lesões induzidas pelo HPV. Rev Bras Ginecol Obstet. 2005;27(2):51-7.

Como citar este artigo:

Maciel LC, Nascimento LF, Elias CP, Rodrigues BS, Oliveira FL, Bertti RO. Análise da ultra-sonografia como método de rastreamento populacional de tumor renal. Rev Col Bras Cir. [periódico na Internet] 2007; 34(6). Disponível em URL: http://www.scielo.br/rcbc

Endereço para Correspondência:

Dr. Luiz Carlos Maciel

Rua Moacir Pereira da Silva, 312

Vila São Geraldo

12062-183 - Taubaté - SP

E-mail: luizmaciel@uol.com.br 